\title{
HPV molecular detection from urine versus cervical samples: an alternative for HPV screening in indigenous populations
}

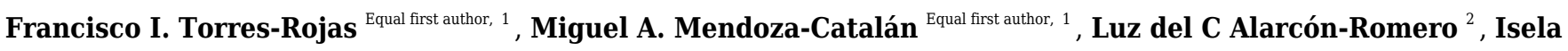 \\ Parra-Rojas ${ }^{3}$, Sergio Paredes-Solís ${ }^{4}$, Marco A. Leyva-Vázquez ${ }^{1}$, Jair E. Cortes-Arciniega ${ }^{1}$, Carlos J. Bracamontes- \\ Benítez $^{1}$, Berenice Illades-Aguiar ${ }^{\text {Corresp. } 1}$ \\ ${ }^{1}$ Laboratorio de Biomedicina Molecular. Facultad de Ciencias Químico Biológicas, Universidad Autónoma de Guerrero, Chilpancingo de los Bravo, \\ Guerrero, Mexico \\ 2 Laboratorio de Citopatología e Histoquímica. Facultad de Ciencias Químico Biológicas, Universidad Autónoma de Guerrero, Chilpancingo de los Bravo, \\ Guerrero, Mexico \\ 3 Laboratorio de Investigación en Obesidad y Diabetes, Facultad de Ciencias Químico Biológicas, Universidad Autónoma de Guerrero, Chilpancingo, \\ Guerrero, México \\ ${ }^{4}$ Centro de Investigación de Enfermedades Tropicales, Universidad Autónoma de Guerrero, Acapulco, Guerrero, México \\ Corresponding Author: Berenice Illades-Aguiar \\ Email address: billades@uagro.mx
}

Background Cervical cancer (CC) is the fourth leading cause of death from neoplasms in women and is caused by the human papilloma virus (HPV). Several methods have been developed for the screening of cervical lesions and HPV; however, some socio-cultural factors prevent women from undergoing gynecological inspection, which results in a higher risk of mortality from cervical cancer in certain population groups as indigenous communities. This study aimed to compare the concordance in HPV detection from urine and cervical samples, to propose an alternative to cervical scraping, which is commonly used in the cervical cancer screening. Methodology The DNA from cervical scrapings and urine samples was extracted using the proteinase $\mathrm{K}$ method followed by precipitation with alcohol, phenol andchloroform; a modification of the proteinase $\mathrm{K}$ method was developed in the management of urine sediment. Viral genotyping was performed using INNOLipa.

Results The study population consisted of 108 patients from an indigenous population at southern Mexico, 32 without squamous intraepithelial lesions (NSIL) and 76 with low squamous intraepithelial lesions (LSIL). The majority of NSIL cervical scrapes were negative for HPV (90.63\%), whereas more than half of LSIL cases were high-risk HPV positive (51.32\%),followed by multiple infection by HR-HPV (17.11\%), and multiple infection by LR- and HR-HPV (9.21\%). No statistically significant relationship between the cytological diagnosis and the HPV genotypes detected in the urine samples was observed. A concordance of $68.27 \%$ for HPV positivity from urine and cervical samples was observed. Similarly, a concordance of $64.52 \%$ was observed in the grouping of HPVs by oncogenic risk. HR-HPV was detected in $71 \%$ of the urine samples from women with LSIL diagnosis, which suggests that HR-HPV detected in a urine sample could indicate the presence or risk 
of developing SIL. Conclusion HR-HPV detection in urine samples could be an initial approach for women at risk of developing LSIL and who, for cultural reasons, refuse to undergo a gynecological inspection. 


\section{HPV molecular detection from urine versus cervical}

\section{2 samples: an alternative for HPV screening in indigenous}

3 populations.

4 Francisco Israel Torres-Rojas ${ }^{1 \dagger}$, Miguel Ángel Mendoza-Catalán ${ }^{1 \dagger}$, Luz del Carmen Alarcón-

5 Romero $^{2}$, Isela Parra-Rojas ${ }^{3}$, Sergio Paredes-Solís ${ }^{4}$, Marco Antonio Leyva-Vázquez ${ }^{1}$, Jair

6 Esteban Cortes-Arciniega ${ }^{1}$, Carlos Jonás Bracamonte-Benítez ${ }^{1}$, Berenice Illades-Aguiar ${ }^{1}$.

7

$8 \quad{ }^{1}$ Laboratorio de Biomedicina Molecular, Facultad de Ciencias Químico Biológicas Universidad

9 Autónoma de Guerrero, Chilpancingo, Guerrero, Mexico.

$10{ }^{2}$ Laboratorio de Citopatología e Histoquímica, Facultad de Ciencias Químico Biológicas

11 Universidad Autónoma de Guerrero, Chilpancingo, Guerrero, Mexico.

$12{ }^{3}$ Laboratorio de Investigación en Obesidad y Diabetes, Facultad de Ciencias Químico Biológicas

13 Universidad Autónoma de Guerrero, Chilpancingo, Guerrero, Mexico.

$14{ }^{4}$ Centro de Investigación de Enfermedades Tropicales, Universidad Autónoma de Guerrero,

15 Acapulco, Guerrero, Mexico.

17 TThese authors contributed equally to this work.

18 Corresponding Author:

19 Berenice Illades-Aguiar ${ }^{1}$

20 Av. Lázaro Cárdenas, Chilpancingo, Guerrero, Mexico.

21 Email address: billades@uagro.mx 
38

39

40

41

42

43

44

45

46

47

48

49

50

51

52

53

54

55

56

57

58

59

60

61

62

63

64

65

66

67

68

69

70

71

72

73

74

75

76

77

78

\section{Abstract \\ Background}

Cervical cancer (CC) is the fourth leading cause of death from neoplasms in women and is caused by the human papilloma virus (HPV). Several methods have been developed for the screening of cervical lesions and HPV; however, some socio-cultural factors prevent women from undergoing gynecological inspection, which results in a higher risk of mortality from cervical cancer in certain population groups as indigenous communities. This study aimed to compare the concordance in HPV detection from urine and cervical samples, to propose an alternative to cervical scraping, which is commonly used in the cervical cancer screening.

\section{Methodology}

The DNA from cervical scrapings and urine samples was extracted using the proteinase $\mathrm{K}$ method followed by precipitation with alcohol, phenol andchloroform; a modification of the proteinase $\mathrm{K}$ method was developed in the management of urine sediment. Viral genotyping was performed using INNOLipa.

\section{Results}

The study population consisted of 108 patients from an indigenous population at southern Mexico, 32 without squamous intraepithelial lesions (NSIL) and 76 with low squamous intraepithelial lesions (LSIL). The majority of NSIL cervical scrapes were negative for HPV $(90.63 \%)$, whereas more than half of LSIL cases were high-risk HPV positive $(51.32 \%)$, followed by multiple infection by HR-HPV (17.11\%), and multiple infection by LR- and HR-HPV (9.21\%). No statistically significant relationship between the cytological diagnosis and the HPV genotypes detected in the urine samples was observed. A concordance of $68.27 \%$ for HPV positivity from urine and cervical samples was observed. Similarly, a concordance of $64.52 \%$ was observed in the grouping of HPVs by oncogenic risk. HR-HPV was detected in $71 \%$ of the urine samples from women with LSIL diagnosis, which suggests that HR-HPV detected in a urine sample could indicate the presence or risk of developing SIL.

\section{Conclusion}

HR-HPV detection in urine samples could be an initial approach for women at risk of developing LSIL and who, for cultural reasons, refuse to undergo a gynecological inspection.

\section{Introduction}

Cervical cancer (CC) is the third most frequent neoplasm in women in the world and the second most frequent among those who are 15-44 years old (Arbyn et al., 2020). Almost all CC cases are related to high-risk human papillomavirus (HR-HPV) infection, with HPV16 and HPV18 being the most common HR-HPVs in CC (Téguété et al., 2017; Chan et al., 2019). The progression of cervical cancer involves premalignant transition stages, which are known as squamous intraepithelial lesions of low or high degree according to the Bethesda System (LSIL or HSIL, respectively) (Nayar and Wilbur 2015). Multiple HPV infection is very common in the diagnosis of precursor lesions. It has also been proposed that diverse HPVs can develop synergism in the cell, which could be associated with the progress of lesions (Sohrabi and Hajia 2017). 
79 Clinical diagnosis is focused on the cellular morphological changes caused by HPV infection.

80 The Papanicolaou test is considered the gold standard for early detection of cervical carcinoma,

81 however, the Pap test results should not be considered to be a determinant criterion in the

82 treatment decision (Sayyah-Melli et al., 2019; Kitchen and Cox 2020). It is highly recommended

83 that the cytological diagnosis via the Pap test be complemented with molecular HPV detection to

84 increase the certainty of the diagnosis and maximize cancer prevention.

85 Samples for molecular HPV detection must be collected by trained personnel (Mittal and Yadav 86 2019), however, in some populations, such as the Nahuatl in Mexico, collection of this type of 87 sample by medical personnel is often not allowed (Graham \& Mishra 2011; Giorgi-Rossi et al., 88 2014). Hence, it is necessary to propose alternatives for sampling. In Mexico, the cervical cancer 89 screening program is focused on the detection of cervical premalignant lesions using the Pap test, 90 in sexually active women from 25 to 34 years old, and HPV detection in women from 35 to 64 91 years old with repetition every 5 years when the Pap test is negative (CNEGSR, 2015). Although 92 this service is free of charge in any institution of the National Health System, many women, 93 mainly those who belong to indigenous communities, refuse a gynecological inspection for 94 cultural reasons. Therefore, it is highly important to identify less invasive screening alternatives 95 to include this type of population.. The proposed options to replace the Pap test include the self96 sampling method (Dzuba et al., 2002); sampling through cervicovaginal washes (Nobbenhuis et 97 al., 2002); and, interestingly, urine, which, in recent reports has been detailed as a useful 98 alternative for HPV detection (Pattyn et al., 2019b; Lefeuvre et al., 2020). Most studies focused 99 on HPV detection from urine have worked with the first urine of the day and the extraction of 100 DNA using commercial kits (Khunamornpong et al., 2016; Nilyanimit et al., 2017). To date, no studies have investigated the Nahuatl indigenous community, whose sociodemographic characteristics such as gender perspectives and low access to health systems (Leyva-Flores et al., 2013), make it vulnerable to HPV infection. In adittion, data relating to the level of concordance in the diagnostic tests between cervical scraping and urine are scarce. To address the above, this work aims to determine the concordance between the molecular detection of HPV in Nahuatl from urine and cervical scraping samples, the latter being considered the gold standard, using an efficient and low-cost method for DNA extraction from urine samples. 
110 Materials and Methods

111

\section{Study population}

113 This study was conducted in the Nahuatl indigenous communities of Xalitla, San Juan

114 Tetelcingo, San Agustín Oapan, San Miguel Tecuixiapan, and Ahuehuepan in the municipality

115 of Tepecuoacuilco de Trujano, which is located in the northern part of the state of Guerrero,

116 Mexico. Indigenous women were invited to participate in the study by calling with loudspeakers

117 in the Nahuatl language and subsequently visiting homes. The invitation was for women to

118 attend their community health center, to have a Pap smear, for the molecular detection of HPV in

119 cervical scrapings and urine samples. The women who attended the health center were surveyed

120 to determine their age, schooling, gynecological-obstetrical background, knowledge of cervical

121 cancer, and whether they had had a Pap smear. The visit to the communities and the recruitment

122 of the women who decided to participate in the study took place from September to November

123 2019. The research protocol was approved by the Ethics Committee of the Universidad

124 Autonóma de Guerrero under identification number 03/07/2019 and the participating women

125 signed informed consent.

126

\section{Specimen collection and preparation}

128 The women included in the study had an exo-endocervical sample taken for the Pap smear and cervical HPV detection. The cervical specimen was collected using a cervix brush directed at the transformation zone (TZ) and an Ayre wooden spatula for ectocervix zone sampling of the uterine cervix and placed into PreservCyt solution (Cytyc Corporation, Marlborough, MA) for liquid-based cytology. In addition, another cervical specimen for HPV detection was collected using a Dacron swab and placed in universal collection medium (UCM) (Digene Corporation, Gaithersburg, MD). Both samples were transferred to Facultad de Ciencias Químico Biológicas (FCQB) and stored at room temperature, until the Pap smear and HPV-molecular detection. In addition, the patients were asked for a sample from the first-void urine, collected themselves in a $10 \times 60 \mathrm{~mL}$ plastic urine collection specimen bottle, stored at $4{ }^{\circ} \mathrm{C}$ for a maximum period of 72 hours, and transferred to FCQB. A quantity of $15 \mathrm{ml}$ of urine was centrifuged at $3500 \mathrm{rpm}$ for 20 
140 detection/genotyping were subsequently performed. Another fraction of the sample was used for 141 dipstick urinalysis.

142

\section{Dipstick Urinalysis}

144 Dipstick urinalysis was performed using Combur 10-Test M strips according to manufacturer 145 instructions. Briefly, 10-15 mL was taken from the specimen container and one strip was 146 submerged for 15-30 seconds; then, the strip was read with reference to the scale printed on the

147 packaging. The strips had reagent pads for the semiquantitative assessment of density, $\mathrm{pH}$,

148 leukocyte esterase, nitrite, protein, glucose, ketones, urobilogen, bilirubin, and

149 hemoglobin/myoglobin.

150

\section{Cytological diagnosis}

152 The cytological diagnosis of the exo-endocervical samples was performed according to the 153 Bethesda System (Solomon et al., 2002; Nayar and Wilbur 2015). Slides with the cytological 154 smears of the TZ for conventional cytology examination were fixed in ethanol for $10 \mathrm{~min}$. The 155 slides were then stained using the Papanicolaou kit (cat. no. 64294; Hycel, Chemical Reagents).

156 Briefly, the slides were hydrated in a descending alcohol series and then incubated at room 157 temperature for $45 \mathrm{sec}$ with Harris hematoxylin to stain the nuclei. Additionally, Orange G 158 colorant was added and incubated at room temperature for $80 \mathrm{sec}$, followed by EA-50 incubated 159 at room temperature for $3 \mathrm{~min}$, which stained the eosinophils and basophils cells, respectively. 160 The slides were then cleared with Xylol reagent prior to microscopic observation (DM1000 161 LED; Leica Microsystems, Inc.; magnification, 10x-20x).

162 Alternatively, the samples for liquid-based cytology were processed according to the 163 manufacturer's protocol of liquid-PREPTM (LGM International, Inc.). Briefly, a clearing solution 164 was added to each sample and then the samples were centrifuged at $1000 \times \mathrm{g}$ for 5 min at room 165 temperature. The supernatant was discarded after the addition of the cell base solution, which 166 conserved the pellet. The samples were mixed and $10 \mu \mathrm{l}$ was added to the slide, which was fixed 167 at room temperature with ethanol for $10 \mathrm{~min}$, following by staining using the Papanicolaou kit 168 and microscopic observation (DM1000 LED; Leica Microsystems, Inc.; magnification, 10x$16920 x)$. 


\section{DNA extraction and integrity}

172 DNA was extracted from cervical scrapes via the phenol-chloroform-isoamyl alcohol method 173 (Ausubel et al., 1995) following proteinase $\mathrm{K}$ digestion at $64^{\circ} \mathrm{C}$ for 45 minutes. For the 174 extraction of DNA from the urine pellet, proteinase K was added, and then the sample was 175 incubated in a water bath for 15 minutes and subsequently incubated at $55^{\circ} \mathrm{C}$ overnight. Finally, 176 the phenol-chloroform-isoamyl alcohol procedure was performed. The DNA recovered was 177 diluted in DEPC water and quantified by spectrophotometry. Although a DNA purity $178(260 / 230 \mathrm{~nm}$ absorbance ratio) $\geq 1.6$ is suggested for an optimal PCR result (Gallagher 2001), 179 we considered a DNA purity $\geq 1.4$ as suitable for viral genotyping, considering the DNA integrity 180 determined through $\beta$-globin gene detection, thereby, 108 samples were considered to be viable 181 (Supplementary Figure 1).

182

183

\section{HPV detection and genotyping}

185

186

187

188

189

190

191

192

193

194

195

196

197

198

199

200

201

The DNA was subjected to an HPV genotyping assay using an INNO-LiPA HPV Genotyping Extra II assay (INNO-LiPA; Fujirebio Europe, Ghent, Belgium) according to the manufacturer's instructions. This system amplifies a 65-bp fragment of the L1 open reading frame and enables the identification of 32 HPV genotypes including 13 high-risk types (HPV 16, 18, 31, 33, 35, 39, 45, 51, 52, 56, 58, 59, and 68), six probable high-risk types (HPV 26, 53, 66, 70, 73 and 82), and thirteen low-risk or unknown risk types (HPV 6, 11,40, 42, 43, 44, 54, 61, 62, 67, 81, 83 and 84). For data analysis, the HPVs detected in the samples were grouped according to oncogenic risk, as HR-HPV, LR-HPV, multiple infection by LR- and HR-HPV (MI LR/HR-HPV), and unidentified HPV infection (HPV-X).

\section{Statistical analysis}

Data capture and statistical analysis were performed with the statistical program STATA 14.0 (College Station, TX: StataCorp LP). Qualitative variables were analyzed by chi-square test $\left(\mathrm{X}^{2}\right)$ or Fisher's exact test as appropriate.In quantitative variables, the Shapiro-Wilk test was carried out for normality determination and the Mann-Whitney test was applied for comparison between two groups. Finally, the sensitivity, specificity, and concordance (Cohen's Kappa coefficient) 
202 were calculated, considering HPV detection from cervical scrapings as the reference. A Kappa 203 value of less than 0.20 indicates poor agreement, $0.21-0.40$ moderate agreement, $0.61-0.80$ good 204 agreement and $0.81-1.00$ very good agreement. $p$ values $\leq 0.05$ were considered statistically 205 significant (Brennan and Silman 1992).

206

207

208

\section{Results}

209

After carrying out sensitization in the indigenous communities, 155 indigenous women attended

210 the health centers and were surveyed: 24 from Ahuehuepan (20.34\% of the total number of attendess), 30 from San Agustín Oapan (27.03\%), 29 from San Juan Tetelcingo (40.28\%), 41 from San Miguel Tecuixiapan (44.09\%) and 31 (25.85\%) from Xalitla of the municipality of Tepecoacuilco, Guerrero, Mexico. The median age was 47.5 years, $62 \%$ of the women had not gone to school, $62 \%$ did not consume alcohol, $81 \%$ had had a Pap smear but mentioned that on many occasions they had not been given the results, and more than $90 \%$ did not know about cervical cancer (data not shown). Of the 155 women surveyed, 108 appropriate cervical scrapings and 104 urine samples were obtained. This difference occurred because some of the women did not agree to undergo a cervical scraping (7.74\%), others were menstruating $(4.52 \%)$, and some of the urine samples did not have the appropriate DNA purity for processing (18.06\%). Cytological analysis showed that 32 women did not have squamous intraepithelial lesions (NSIL) and 76 had low squamous intraepithelial lesions (LSIL). The median ages of the women were $49.0(39.0-55.0)$ and $45.5(29.0-56.5)$ years in the NSIL and LSIL groups, respectively. The clinical and pathological characteristics are summarized in Table 1. In this population, only a greater number of sexual partners showed a statistically significant relationship with LSIL (Table 1).

\section{HPV positivity in cervical and urine samples}

As expected, based on analysis the cervical samples, a statistically significant relationship was observed between the HPV-oncogenic risk detected and cytological diagnosis $(p=0.001)$. The NSIL samples were significantly negative to HPV $(90.63 \%)$, whereas LSIL cases were positive to HR-HPV (51.32 \%), followed by multiple infection by HR-HPV (17.11\%), and multiple infection by LR- and HR-HPV (9.21 \%), (Table 2). By contrast, no statistically significant relationship between the cytological diagnosis and the HPV genotypes detected in the urine 
233 samples was observed $(p=0.33)$. The most frequent HR-HPV genotypes detected in cervical 234 samples were HPV-52 (10/108 cases), followed by HPV-58 and HPV-59 (9/108 cases), whereas 235 the most frequent HR-HPV genotypes in urine samples were HPV-39 (21/105), followed by 236 HPV-16 (17/105), HPV-52 (16/105), and HPV-51 (15/105) (Supplementary Table 1). The 237 number of HPV genotypes detected in cervical and urine samples was associated to cytological 238 diagnosis ( $p=0.001$ and $p=0.047$, respectively); In addition, HR-HPV was detected in $71 \%$ (HR$239 \mathrm{HPV}+\mathrm{MI}$ LR/HR-HPV + MI HR-HPV) of urine samples from women with LSIL diagnosis 240 (Table 2).

241

242

Concordance between urine and cervical samples for HPV detection

A positive agreement of $86.11 \%$ for HPV determined by INNOLiPA from urine and cervical

245 samples was observed, regardless of the viral genotype, however, the total concordance was poor or weak (Kappa $=0.16$, concordance $68.27 \%)($ Table 3$)$. A similar result was observed by grouping the detected HPVs by oncogenic risk; an agreement of $89.6 \%$ in HR-HPV positivity between urine and cervical samples was observed (Kappa $=0.16$, concordance $64.52 \%)($ Table 4). The sensitivity and specificity of HR-HPV positivity in urine, using cervical scrapings as reference, were $89.7 \%$ and $25.7 \%$, respectively.

251

252

253

\section{Discussion}

Currently, cervical cancer (CC) is the third most frequent neoplasm in women in the world 255 (Arbyn et al., 2020), and nearly 100\% of CC cases are related to high-risk human papillomavirus (HR-HPV) infection (Hooi et al., 2018; Chan et al., 2019). In developing countries, cancer mortality and morbidity are higher than those in developed countries, and an elevated cervical cancer-related mortality has been reported mainly in indigenous women. This suggests structural, social, or individual barriers to screening contribute to the poor prognosis of cancer cases in indigenous women (Cramb et al., 2012; Vasilevska et al., 2012).

262 The factors determining the high prevalence of cervical cancer in Mexico, particularly in 263 Guerrero State, include the socio-cultural characteristics of the population, lack of marital 
264 support for screening, cultural taboos, stigmatization of women with this neoplasm, and, finally, 265 the limited information regarding the procedure for early diagnosis of HPV infection (Nilyanimit 266 et al., 2017). In addition, indigenous populations have low detection coverage, and many 267 indigenous women refuse gynecological inspection due to cultural barriers, such as shame, or 268 prohibition by their husband or other women in the community. These factors block timely HPV 269 detection and increase the risk of developing premalignant lesions.

270

Although gynecological inspection via the Papanicolaou test and HPV molecular detection are

272 the most important methods for screening of premalignant lesions of cervical cancer, it is

273 important to identify less invasive alternatives to obtain useful samples for HPV detection.

274 Therefore, this study evaluated the concordance of HPV molecular detection from two different 275 samples, cervical scraping, and urine, to evaluate urine as a potential alternative for screening in 276 indigenous communities.

277

278 In the indigenous population studied, only the number of sexual partners was found to show a 279 relationship with LSIL (Table 1), which is in agreement with previous reports that indicate a 280 close relationship of this factor with the development of cervical neoplasm (Herrero et al., 1990; 281 Itarat et al., 2019). Other factors such, as parity and age of first sexual encounter, have been 282 related to premalignant lesions and cervical cancer development (Lukac et al., 2018; Kashyap et 283 al., 2019).

284

Interestingly, in this study population HPV-52 was most frequent detected in cervical scrapings. This finding did not agree with previous reports in the region indicating that HPV-16 and HPV18 are most frequent (Illades-Aguiar et al., 2009; Illades-Aguiar et al., 2010). Previous findings indicate differences in the HPV distribution between ethnic groups (Lin et al., 2015; Baloch et al., 2017). In this regard, is important to note that the analyzed population belongs to a socioeconomic zone with a high of migration rate (about 78\%) and this situation can cause changes in the prevalence of sexually transmitted infections in the community (OMS 2003; Platt et al., 2013). One of the most important characteristics in the progression of cervical lesions is the presence of several viral genotypes. Thus, a finding of this study that should be noted, as 
295 common finding in precursor lesions, as previously reported (Schmitt et al., 2013; Aguilar-

296 Lemarroy et al., 2015).

297

298 The potential HPV detection from urine has been previously described by various authors;

299 however, most have suggested performing DNA extraction using commercial kits (Brinkman et 300 al., 2002; Cuzick et al., 2017; Pattyn et al., 2019b), which would increase the cost of the test and 301 the difficulty of using urine samples as a feasible option for HPV screening. In this study, the 302 DNA was extracted from both type of samples using the common phenol-chloroform-isoamyl 303 alcohol method. Thus, DNA with adequate quality was obtained for molecular HPV detection, 304 which was determined by reviewing the DNA integrity via $\beta$-globin gene detection. Molecular 305 HPV detection from urine and cervical scraping samples may be similar in terms of cost, 306 however, the importance of the use of urine samples is that it is a non-invasive method, and 307 could be a useful alternative for women who refuse the gynecological inspection.

308 Different HPV genotypes were detected in urine samples compared to cervical scrapings; for 309 instance, HPV 16 and HPV 39 were more frequent in urine in comparison with cervical samples 310 (Supplementary Table 1). Similarly, in a study in Chilean women, no significant differences in 311 HPV detection and genotyping between the cervical and urine samples were observed. In some 312 cases, the detection of carcinogenic HPV was positive in the cervical but negative in the urine 313 samples, whereas in a similar number of cases, samples were positive for HR-HPV detection in 314 urine but negative in cervical samples (Buchegger et al., 2018). In addition, Tanzi and 315 colleagues, (2013), reported that the absolute number of genotypes detected in urine samples was 316 higher than the number of genotypes identified following examination of cervical samples (Tanzi 317 et al., 2013). Other studies have reported that HPV prevalence was similar or higher in another 318 genital regions compared to cervical samples; it was observed that prevalence for any HPV type 319 in vaginal specimens was greater than that in cervical samples, whereas the prevalence for any 320 carcinogenic HPV type in vaginal and cervical specimens was similar, suggesting carcinogenic 321 HPV genotypes could have similar tropism for vaginal and cervical epithelium (Castle et al., 322 2007). One possible explanation for this observation is that HPV of other anatomic sites, such as 323 the urethra, vulva or vagina could be present in the urine sample considering the natural route of 324 this liquid waste (Sehgal et al., 2009, Tanzi et al., 2013, Abelson et al., 2018, Buchegger et al., 325 2018). 
326 A concordance of $68.27 \%$ in HPV detection from urine and the cervix was found (Table 3 ). In 327 addition, one or more HR-HPVs was detected in 71\% of urine samples from women with LSIL 328 diagnosis (Table 2). The above findings suggest that two or more viral genotypes, mainly HR329 HPV, detected in a urine sample could indicate the presence of, risk of developing, SIL.

330 Therefore, urine can be a suitable sample in populations of women who do not accept

331 gynecological inspection to obtain cervical scrapings. Other studies have supported the idea of

332 using urine for HPV detection (Brinkman et al., 2002; Sargent et al., 2019; Pattyn et al., 2019a;

333 Tranberg et al., 2020).

334 A limitation of this study is that there were only two study groups, NSIL and LSIL. With a larger 335 population and at least three study groups (NSIL, LSIL, and HSIL), the concordance in the HPV 336 molecular detection by INNOLiPA from urine and cervical samples could be more evident.

337 Considering the experience gained in this study, in addition to that reported by other relevant 338 studies, we propose a workflow with urine samples for the detection of HPV, focused mainly on

339 HR-HPV, and the possible management of patients (Figure 1). According to the guidelines of the 340 Mexican program for the timely detection of cervical cancer, after a negative result of HPV in 341 cervical scrapings, the test should be conducted every five years (CNEGSR, 2015). In this 342 workflow for HPV screening from urine samples, considering that sensibility of HPV detection 343 from urine samples was $89.7 \%$ in relation to the molecular detection of HPV from cervical 344 scrapings, we proposed that women aged 35-64 years old with a negative result of HR-HPV or 345 positive result of LR-HPV could be considered to be at low risk and their next analysis could be 346 scheduled after four and three years, respectively. In contrast, women who test positive for HR347 HPV could be considered to be at risk of developing squamous intraepithelial lesions of the 348 cervix (SIL) and should be submitted to a Pap test for gynecological inspection to confirm or rule 349 out the presence of lesions and infection by HPV in cervical cells (Figure 1).

350

Although the Pap test continues to be the gold standard for the determination of cervical abnormalities, the molecular detection of HR-HPV in urine samples is a non-invasive method. Thus, it could represent an initial approach for women at risk of developing SIL and a feasible alternative for indigenous women who, due to cultural barriers and poor health services, do not have timely detection of pre-malignant lesions and cervical cancer. 


\section{Conclusions}

358 The use of urine samples for the molecular detection of HPV is a non-invasive method that could

359

360

361

362

363

364

365

366

367

368

369

370

371

372

373

374

375

376

377

378

379

380

381

382

383

384

385

386

387

388

389

390

391

392

393

394

be a good alternative for the screening of women from indigenous populations who, for sociocultural reasons, initially refuse gynecological inspection. Only women who test positive for HR-HPV from a urine sample would be referred to gynecological inspection and the Pap test, to confirm or rule out the presence of cervical lesions and HPV infection.

\section{Acknowledgements}

We want to thank Natividad Sales Linares for her expert technical assistance.

\section{References}

Abelson B, Sun D, Que L, Nebel RA, Baker D, Popiel P, Amundsen CL, Chai T, Close C, DiSanto M, Fraser MO, Kielb SJ, Kuchel G, Mueller ER, Palmer MH, Parker-Autry C, Wolfe AJ and Damaser MS. 2018. Sex differences in lower urinary tract biology and physiology. Biology of sex differences. 9 (1): 45. DOI: 10.1186/s13293-018-0204-8

Aguilar-Lemarroy A, Vallejo-Ruiz V, Cortés-Gutiérrez EI, Salgado-Bernabé ME, RamosGonzález NP, Ortega-Cervantes L, Arias-Flores R, Medina-Díaz IM, Hernández-Garza F, Santos-López G, Piña-Sánchez P, IMSS Research Network on HPV.2015. Human papillomavirus infections in Mexican women with normal cytology, precancerous lesions, and cervical cancer: Type-specific prevalence and HPV coinfections. Journal of Medical Virology, 87(5), 871-884. DOI: 10.1002/jmv.24099

Arbyn M, Weiderpass E, Bruni L, de Sanjosé S, Saraiya M, Ferlay J and Bray F. 2020. Estimates of incidence and mortality of cervical cancer in 2018: a worldwide analysis. Lancet Glob. Health. 8 (2): e191-e203. DOI: 10.1016/S2214-109X(19)30482-6

Ausubel F, Brent R, Kingston R, Moore D, Seidman JG, Smith JA and Struhl K.1995. Short Protocols in Molecular Biology. John Wiley \& Sons, New York.2-3. DOI: 10.1002/bmb.1996.5690240143

Baloch Z, Yasmeen N, Li Y, Ma K, Wu X, Yang SH and Xia X.2017. Prevalence and risk factors for human papillomavirus infection among Chinese ethnic women in southern of Yunnan, China. Braz J Infect Dis. 21 (3): 325-332. DOI: 10.1016/j.bjid.2017.01.009

Brennan P and Silman A. 1992. Statistical methods for assessing observer variability in clinical measures. BMJ. 304 (6840): 1491-4. DOI: 10.1136/bmj.304.6840.1491

Brinkman JA, Jones WE, Gaffga AM, Sanders JA, Chaturvedi AK, Slavinsky III J, Clayton JL, Dumestre J and Hagensee ME. 2002. Detection of human papillomavirus DNA in urine specimens from human immunodeficiency virus-positive women. Journal of clinical microbiology. 40 (9): 3155-3161. DOI: 10.1128/jcm.40.9.3155-3161.2002

Buchegger K, Viscarra T, Andana A, Ili C, López J, Zanella L, Carmona-López MI, Fernández JJ, Espinel IC, Sánchez R, Roa JC and Brebi P. 2018. Detection and genotyping of 
395

396

397

398

399

400

401

402

403

404

405

406

407

408

409

410

411

412

413

414

415

416

417

418

419

420

421

422

423

424

425

426

427

428

429

430

431

432

433

434

human papillomavirus virus (HPV): a comparative analysis of clinical performance in cervical and urine samples in Chilean women. Int J Clin Exp Pathol. 11 (11): 5413-5421.

Castle PE, Rodriguez AC, Porras C, Herrero R, Schiffman M, Gonzalez P, Hildesheim A and Burk RD. 2007. A comparison of cervical and vaginal human papillomavirus. Sexually transmitted diseases. 34 (11), 849-855. DOI: 10.1097/OLQ.0b013e318064c8c5

Centro Nacional de Equidad de Género y Salud Reproductiva (CNEGSR). 2015. Prevención y Control del Cáncer de la Mujer. Available at https://www.gob.mx/salud/cnegsr/es/acciones-y-programas/prevencion-y-deteccion-oportunadel-cancer-de-cuello-uterino (Accesed 20 March 2021).

Chan CK, Aimagambetova G, Ukybassova T, Kongrtay K and Azizan A. 2019. Human Papillomavirus Infection and Cervical Cancer: Epidemiology, Screening, and VaccinationReview of Current Perspectives. J Oncol. (2019): 3257939. DOI: 10.1155/2019/3257939

Cramb SM, Garvey G, Valery PC, Williamson JD, and Baade PD. 2012. The first year counts: cancer survival among indigenous and non-indigenous Queenslanders, 1997-2006. Med. J. Aust. 196: 270-274. DOI: 10.5694/mja11.11194

Cuzick J, Cadman L, Ahmad AS, Ho L, Terry G, Kleeman M, Lyons D, Austin J, Stoler MH, T Vibat CR, Dockter J, Robbins D, Billings PR and Erlander MG. 2017. Performance and Diagnostic Accuracy of a Urine-Based Human Papillomavirus Assay in a Referral Population. Cancer Epidemiol Biomarkers Prev. 26 (7): 1053-1059. DOI: 10.1158/1055-9965.EPI-16-0960

Dzuba IG, Díaz-Yunes E, Allen B, Flores-Leonard Y, Lazcano-Ponce EC, Shah KV, Bishai D, Lorincz A,Ferris D, Turnbull B, Hernández-Avila M and Salmerón J. 2002. The acceptability of self-collected samples for HPV testing vs. the pap test as alternatives in cervical cancer screening. J Womens Health Gend Based Med. 11 (3): 265-275. DOI: $10.1089 / 152460902753668466$

Gallagher S. (2001). Quantitation of nucleic acids with absorption spectroscopy. Curr Protoc Protein Sci. Appendix 4:Appendix 4K. DOI: 10.1002/0471140864.psa04ks13

Giorgi-Rossi P, Baldacchini F and Ronco G. 2014. The Possible Effects on SocioEconomic Inequalities of Introducing HPV Testing as Primary Test in Cervical Cancer Screening Programs. Frontiers in oncology. (4): 20. DOI: 10.3389/fonc.2014.00020

Graham JE and Mishra A. 2011. Global challenges of implementing human papillomavirus vaccines. International journal for equity in health. (10) 27. DOI: 10.1186/1475-9276-10-27

Herrero R, Brinton LA, Reeves WC, Brenes MM, Tenorio F, de Britton RC, Gaitán E, Montalván, García and Rawls WE. 1990. Risk factors for invasive carcinoma of the uterine cervix in Latin America. Bull Pan Am Health Organ. 24 (3): 263-83.

Hooi DJ, Lissenberg-Witte BI, de Koning MNC, Pinedo HM, Kenter GG, Meijer CJ and Quint WG. 2018. High prevalence of high-risk HPV genotypes other than 16 and 18 in cervical cancers of Curaçao: implications for choice of prophylactic HPV vaccine. Sex Transm Infect. 94 (4): 263-267. DOI: 10.1136/sextrans-2017-053109

Illades-Aguiar B, Cortés-Malagón EM, Antonio-Véjar V, Zamudio-López N, AlarcónRomero LdelC, Fernández-Tilapa G, Hernández-sotelo D, Terán-Porcayo MA, Flores-Alfaro E 
435

436

437

438

439

440

441

442

443

444

445

446

447

448

449

450

451

452

453

454

455

456

457

458

459

460

461

462

463

464

465

466

467

468

469

470

471

472

473

and Leyva-Vázquez MA. 2009. Cervical carcinoma in Southern Mexico: Human papillomavirus and cofactors. Cancer Detect Prev. 32 (4): 300-307. DOI: 10.1016/j.cdp.2008.09.001

Illades-Aguiar B, Alarcón-Romero Ldel C, Antonio-Véjar V, Zamudio-López N, SalesLinares N, Flores-Alfaro E, Fernández-Tilapa G, Vences-Velázquez A, Muñoz-Valle JF and Leyva-Vázquez MA. 2010. Prevalence and distribution of human papillomavirus types in cervical cancer, squamous intraepithelial lesions, and with no intraepithelial lesions in women from Southern Mexico. Gynecol Oncol.117 (2): 291-296. DOI: 10.1016/j.ygyno.2010.01.036

Itarat Y, Kietpeerakool C, Jampathong N, Chumworathayi B, Kleebkaow P, Aue-Aungkul A, and Nhokaew W.2019. Sexual behavior and infection with cervical human papillomavirus types 16 and 18. International journal of women's health. (11): 489-494. DOI: 10.2147/IJWH.S218441

Kashyap N, Krishnan N, Kaur S, and Ghai S. 2019. Risk Factors of Cervical Cancer: A Case-Control Study. Asia-Pacific journal of oncology nursing. 6 (3), 308-314. DOI: 10.4103/apjon.apjon_73_18

Kitchen FL and Cox CM. 2020. Papanicolaou Smear. In: StatPearls [Internet]. Treasure Island (FL): StatPearls Publishing; 2021 Jan-..

Khunamornpong S, Settakorn J, Sukpan K, Lekawanvijit S, Katruang N and Siriaunkgul S. 2016. Comparison of Human Papillomavirus Detection in Urine and Cervical Samples Using High-Risk HPV DNA Testing in Northern Thailand. Obstet Gynecol Int2016:6801491. DOI: 10.1155/2016/6801491

Lefeuvre C, Pivert A, Guillou-Guillemette HL, Fabiani FL, Veillon P, Banaszuk ASLD and Ducancelle A. 2020. Urinary HPV DNA testing as a tool for cervical cancer screening in women who are reluctant to have a Pap smear in France. J Infect. 81 (2): 248-254.

DOI:10.1016/j.jinf.2020.05.006.

Leyva-Flores R, Infante-Xibille C, Gutiérrez JP and Quintino-Pérez F. 2013. Inequidad persistente en salud y acceso a los servicios para los pueblos indígenas de México, 2006-2012. Salud Pública de México. 55 (Sup1. 2): S123-S128.

Lin L, Benard VB, Greek A, Hawkins NA, Roland KB, and Saraiya M. 2015. Racial and ethnic differences in human papillomavirus positivity and risk factors among low-income women in Federally Qualified Health Centers in the United States. Preventive medicine. 81, 258261. DOI: 10.1016/j.ypmed.2015.08.027

Lukac A, Sulovic N, Smiljic S, Ilic AN, \& Saban O. 2018. The Prevalence of the Most Important Risk Factors Associated with Cervical Cancer. Materia socio-medica. 30 (2), 131135. DOI: $10.5455 / \mathrm{msm} .2018 .30 .131-135$

Mittal B andYadav S. 2019 Molecular Diagnosis of Cervical Cancer. In: Shukla K., Sharma P., Misra S. (eds) Molecular Diagnostics in Cancer Patients. Springer, Singapore. DOI:10.1007/978-981-13-5877-7_8

Nayar R and Wilbur DC. The Pap test and Bethesda 2014. 2015. Cancer Cytopathol. 123 (5): 271-81. DOI: $10.1002 /$ cncy.21521 
474

475

476

477

478

479

480

481

482

483

484

485

486

487

488

489

490

491

492

493

494

495

496

497

498

499

500

501

502

503

504

505

506

507

508

509

510

511

512

Nilyanimit P, Chansaenroj J, Karalak A, Laowahutanont P, Junyangdikul P and Poovorawan Y. 2017. Comparison of human papillomavirus (HPV) detection in urine and cervical swab samples using the HPV GenoArray Diagnostic assay. PeerJ (5): e3910. DOI: 10.7717/peerj.3910

Nobbenhuis MAE, Helmerhorst TJM, van den Brule AJC, Rozendaal L, Jaspars LH, Voorhorst FJ, Verheijen RHM and Meijer CJLM.. 2002. Primary screening for high risk HPV by home obtained cervicovaginal lavage is an alternative screening tool for unscreened women. $J$ Clin Pathol. 55 (6): 435-439. DOI: 10.1136/jcp.55.6.435

Pattyn J, Van Keer S, Biesmans S, Ieven M, Vanderborght C, Beyers K, Vankerckhoven V, Bruyndonckx R, Van Damme P and Vorsters A. 2019a. Human papillomavirus detection in urine: Effect of a first-void urine collection device and timing of collection. $J$ Virol Methods. 264: 23-30. DOI: 10.1016/j.jviromet.2018.11.008

Pattyn J, Van Keer S, Téblick L, Van Damme P and Vorsters A. 2019b. HPV DNA detection in urine samples of women: 'an efficacious and accurate alternative to cervical samples?'. Expert Rev Anti Infect Ther. 17 (10): 755-757. DOI: 10.1080/14787210.2019.1668776

Platt L, Grenfell P, Fletcher A, Sorhaindo A, Jolley E, Rhodes T and Bonell C. 2013. Systematic review examining differences in HIV, sexually transmitted infections and healthrelated harms between migrant and non-migrant female sex workers. Sex Transm Infect. 89 (4): 311-319. DOI: 10.1136/sextrans-2012-050491

Sargent A, Fletcher S, Bray K, Kitchener HC and Crosbie EJ. 2019. Cross-sectional study of HPV testing in self-sampled urine and comparison with matched vaginal and cervical samples in women attending colposcopy for the management of abnormal cervical screening. BMJ Open. 9 (4): e025388. DOI: 10.1136/bmjopen-2018-025388

Sayyah-Melli M, Rahmani V, Ouladsahebmadarek E, Jafari-Shobeiri M, Gharabaghi PM and Vahidi MN. 2019. Diagnostic Value of Pap Smear and Colposcopy in Non-benign Cervical Lesions. International Journal of Women's Health and Reproduction Sciences. 7 (2): 211-215. DOI: 10.15296/ijwhr.2019.35

Schmitt M, Depuydt C, Benoy I, Bogers J, Antoine J, Arbyn M, Pawlita M and VALGENT Study Group. 2013. Multiple human papillomavirus infections with high viral loads are associated with cervical lesions but do not differentiate grades of cervical abnormalities. Journal of clinical microbiology. 51(5), 1458-1464. DOI: 10.1128/JCM.00087-13

Sehgal A, Gupta S, Parashari A, Sodhani P and Singh V. 2009. Urine HPV-DNA detection for cervical cancer screening: prospects and prejudices. J Obstet Gynaecol. 29 (7): 583-9. DOI: $10.1080 / 01443610903061736$

Sohrabi A and Hajia M. 2017. Cervical Cancer and Genital Infections: Assessment of Performance and Validation in Human Papillomavirus Genotyping Assays in Iran, its Neighbouring Countries and Persian Gulf Area. Iranian journal of pathology. 12(1), 35-4.

Solomon D, Davey D, Kurman R, Moriarty A, O'Connor D, Prey M, Raab S, Sherman M, Wilbur D, Wright Jr T, Young N, Forum Group Mmebers and Bethesda 2001 Workshop. 2002. 
513 The 2001 Bethesda System: terminology for reporting results of cervical cytology. JAMA.

514 2002;287:2114-9. DOI: 10.1001/jama.287.16.2114.

515 Tanzi E, Bianchi S, Fasolo MM, Frati ER, Mazza F, Martinelli M, Colzani D, Beretta R, 516 Zappa A and Orlando G. 2013. High performance of a new PCRbased urine assay for HPV-DNA 517 detection and genotyping. J Med Virol. 85: 91-8. DOI: 10.1002/jmv.23434

518 Téguété I, Dolo A, Sangare K, Sissoko A, Rochas M, Beseme S, Tounkara K, Yekta S, De

519 Groot AS and Koita OA. 2017. Prevalence of HPV 16 and 18 and attitudes toward HPV

520 vaccination trials in patients with cervical cancer in Mali. PloS one. 12 (2), e0172661. DOI:

521 10.1371/journal.pone.0172661

522 Tranberg M, Skov-Jensen J, Hammer-Bech B, and Andersen B. 2020. Urine collection in 523 cervical cancer screening - analytical comparison of two HPV DNA assays. BMC Infectious 524 Diseases.20: 926. DOI: 10.1186/s12879-020-05663-7

525 Vasilevska M, Ross SA, Gesink D and Fisman DN. 2012. Relative risk of cervical cancer 526 in indigenous women in Australia, Canada, New Zealand, and the United States: a systematic 527 review and meta-analysis. J Public Health Policy. 33 (2): 148-64. DOI: 10.1057/jphp. 2012.8 528 World Health Organization (WHO). (2003) International Migration, Health \& Human 529 Rights, Health and Human Rights Publication Series, No. 4, Dec., WHO, Switzerland.

530

531 


\section{Table 1 (on next page)}

Clinical characteristics of the indigenous population studied

NSIL, non-squamous intraepithelial lesions; LSIL, low-grade squamous intraepithelial lesions;

C-section, caesarean section; ${ }^{a}$ Median (p25-p75), ${ }^{b}$ Mann Whitney-test, ${ }^{c} X^{2}$ test, ${ }^{d}$ Fisher's exact test. 
Table 1. Clinical characteristics of the indigenous population studied

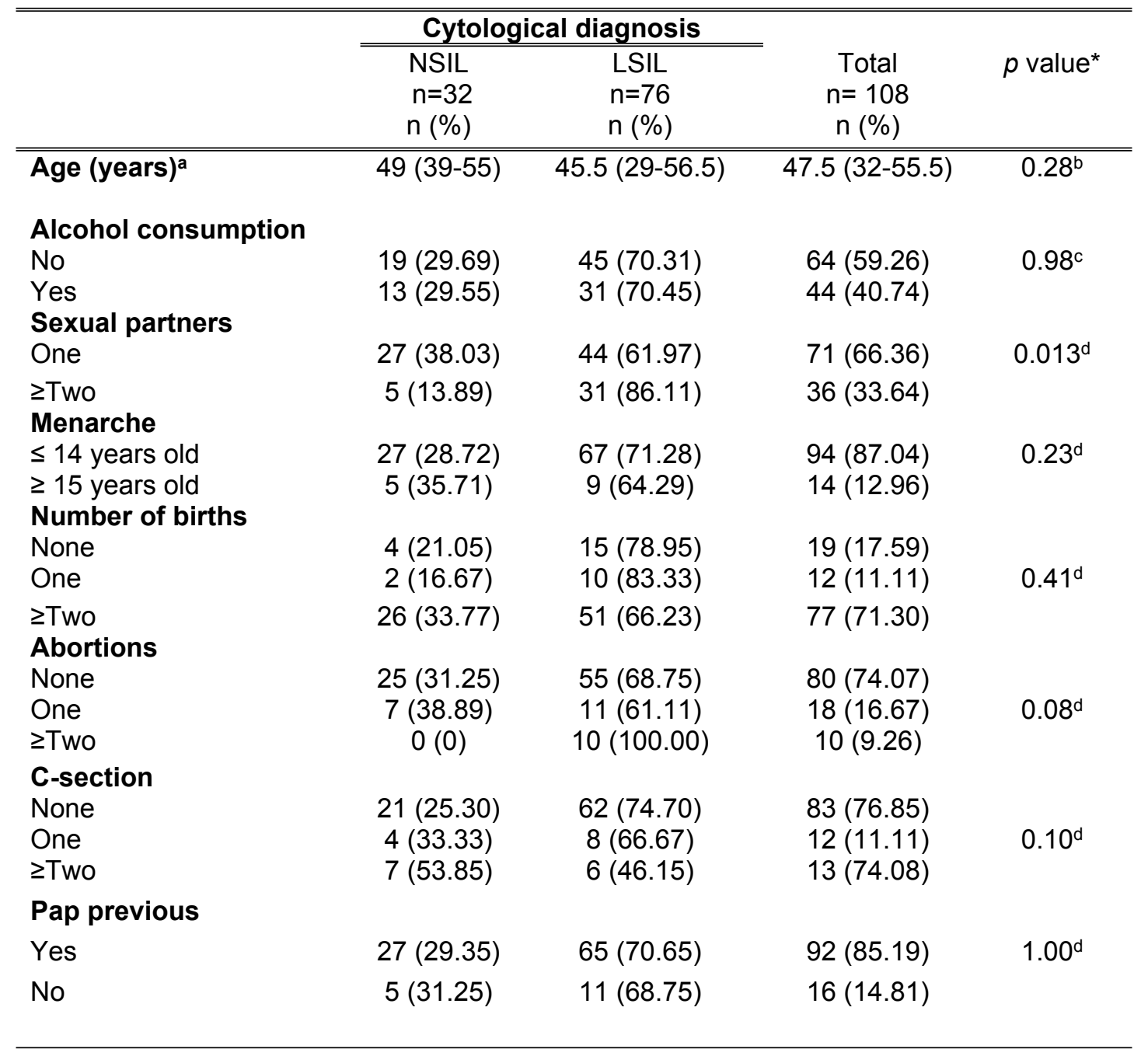

NSIL, non-squamous intraepithelial lesions; LSIL, low-grade squamous intraepithelial lesions; C-section, caesarean section; a Median (p25-p75), 'bann Whitney-test, ' $X^{2}$ test, 'Fisher's exact test. 


\section{Table 2 (on next page)}

HPV infection detected in cervix and urine samples

NSIL, non-squamous intraepithelial lesions; LSIL, low-grade squamous intraepithelial lesions; HPV-LR, low risk HPV infection; HPV-HR, high risk HPV infection; MI LR/HR-HPV, low risk HPV and high risk HPV multiple infection; HPV-X, unidentified HPV; MI, multiple infection; ${ }^{C}$ Fisher's exact test; ${ }^{*} p$ value $\leq 0.05$ was considered as statistically significant. 
Table 2. HPV infection detected in cervix and urine samples

\begin{tabular}{|c|c|c|c|c|}
\hline & \multicolumn{2}{|c|}{ Cytological diagnosis } & \multirow[b]{2}{*}{$\begin{array}{l}\text { Total } \\
\text { n (\%) }\end{array}$} & \multirow[b]{2}{*}{$p$ value $^{*}$} \\
\hline & $\begin{array}{l}\text { NSIL } \\
n(\%)\end{array}$ & $\begin{array}{l}\text { LSIL } \\
\text { n (\%) }\end{array}$ & & \\
\hline \multicolumn{5}{|c|}{ HPV infection in cervix } \\
\hline Negative & $29(90.63)$ & $3(3.95)$ & $32(29.63)$ & \multirow{5}{*}{$0.001^{\mathrm{c}}$} \\
\hline LR-HPV & $0(0)$ & $3(3.95)$ & $3(2.78)$ & \\
\hline HR-HPV & $1(3.13)$ & $39(51.32)$ & $40(37.04)$ & \\
\hline MI LR/HR-HPV & $2(3.13)$ & $20(9.21)$ & $22(7.41)$ & \\
\hline HPV-X & $0(0)$ & $11(14.47)$ & $11(10.19)$ & \\
\hline \multicolumn{5}{|c|}{ HPV infection in urine } \\
\hline $\begin{array}{l}\text { LR-HPV } \\
\text { HR-HPV } \\
\text { MI LR/HR-HPV } \\
\text { X-HPV }\end{array}$ & $\begin{array}{c}1(3.13) \\
10(31.25) \\
10(15.63) \\
2(6.25)\end{array}$ & $\begin{array}{c}3(4.11) \\
18(24.66) \\
34(13.70) \\
8(10.96)\end{array}$ & $\begin{array}{c}4(3.81) \\
28(26.67) \\
44(14.29) \\
10(9.52)\end{array}$ & $0.306^{c}$ \\
\hline \multicolumn{5}{|c|}{ HPV genotypes in cervix } \\
\hline $\begin{array}{l}\text { None } \\
\text { One }\end{array}$ & $\begin{array}{c}29(90.63) \\
1(3.13)\end{array}$ & $\begin{array}{c}3(3.95) \\
53(69.74)\end{array}$ & $\begin{array}{l}32(29.63) \\
54(50.00)\end{array}$ & \multirow[t]{2}{*}{$0.0001^{\circ}$} \\
\hline$\geq$ two (MI) & $2(6.25)$ & $20(26.32)$ & $22(20.37)$ & \\
\hline \multicolumn{5}{|c|}{ HPV genotypes in urine } \\
\hline None & $10(31.25)$ & $9(12.50)$ & $19(18.27)$ & \multirow[b]{2}{*}{$0.047^{c}$} \\
\hline $\begin{array}{l}\text { One } \\
\geq \text { two (MI) }\end{array}$ & $\begin{array}{c}13(40.63) \\
9(28.13)\end{array}$ & $\begin{array}{l}29(40.28) \\
34(47.22)\end{array}$ & $\begin{array}{l}42(40.38) \\
43(41.35)\end{array}$ & \\
\hline
\end{tabular}

NSIL, non-squamous intraepithelial lesions; LSIL, low-grade squamous intraepithelial lesions; HPV-LR, low risk HPV infection; HPV-HR, high risk HPV infection; MI LR/HR-HPV, low risk HPV and high risk HPV multiple infection; HPV$\mathrm{X}$, unidentified HPV; MI, multiple infection; ' ${ }^{C}$ Fisher's exact test; ${ }^{*} p$ value $\leq 0.05$ was considered as statistically significant. 


\section{Table 3(on next page)}

Concordance, sensitivity, and specificity of HPV detection in urine and cervical samples 
1

Table 3. Concordance, sensitivity, and specificity of HPV detection in urine and cervical samples.

\begin{tabular}{lccc}
\hline \hline HPV Detection in & \multicolumn{2}{c}{ Urine HPV detection } & Total \\
Cervical Scraping & HPV positive & HPV negative & $72(69.23)$ \\
\hline HPV positive & $62(86.11)$ & $10(13.89)$ & $32(30.77)$ \\
\hline HPV negative & $23(71.88)$ & $9(28.12)$ & \\
\hline \hline & $85(81.73)$ & Sensitivity: $86.10 \%$ \\
Specificity: $28.10 \%$ & \\
Concordance: $68.27 \%$ & \\
\multicolumn{2}{c}{ Kappa:0.16 } \\
\hline
\end{tabular}

2

3 


\section{Table 4 (on next page)}

Concordance, sensitivity, and specificity in detection of HPV-oncogenic risk groups in urine and cervical samples.

HR-HPV, high risk HPV infection; LR-HPV, low risk HPV infection HR-HPV, high risk HPV infection; LR-HPV, low risk HPV infection 
1

2

Table 4. Concordance, sensitivity, and specificity in detection of HPV-oncogenic risk groups in urine and cervical samples.

\begin{tabular}{|c|c|c|c|c|}
\hline \multirow{2}{*}{$\begin{array}{l}\text { HPV Detection in } \\
\text { Cervical Scraping }\end{array}$} & \multicolumn{3}{|c|}{ Urine HPV detection } & \multirow{2}{*}{$\begin{array}{l}\text { Total } \\
\mathrm{n}=93\end{array}$} \\
\hline & HR-HPV & LR-HPV & HPV Negative & \\
\hline HR-HPV & $52(89.66)$ & $0(0)$ & $6(10.37)$ & $58(62.37)$ \\
\hline LR-HPV & $2(66.67)$ & $1(33.33)$ & $0(0)$ & $3(3.23)$ \\
\hline Negative & $24(75.00)$ & 0 & $8(25.00)$ & $32(34.40)$ \\
\hline & $78(83.87)$ & $1(1.08)$ & $14(15.05)$ & \\
\hline & & $\begin{array}{r}\text { Sensitivity: } \\
\text { Specificity: } \\
\text { Concordance } \\
\text { Kappa: }\end{array}$ & & \\
\hline
\end{tabular}

3 HR-HPV, high risk HPV infection; LR-HPV, low risk HPV infection.

5 


\section{Figure 1}

Workflow proposed for human papillomavirus (HPV) infection screening in indigenous women

Red: The sample is not suitable for analysis; it must be discarded, and a new sample requested from the patient. Green: The sample is suitable for analysis. Blue: HPV negative, no risk of squamous intraepithelial lesions (SIL). Yellow: low risk for SIL. Orange: moderate or high risk for SIL. 


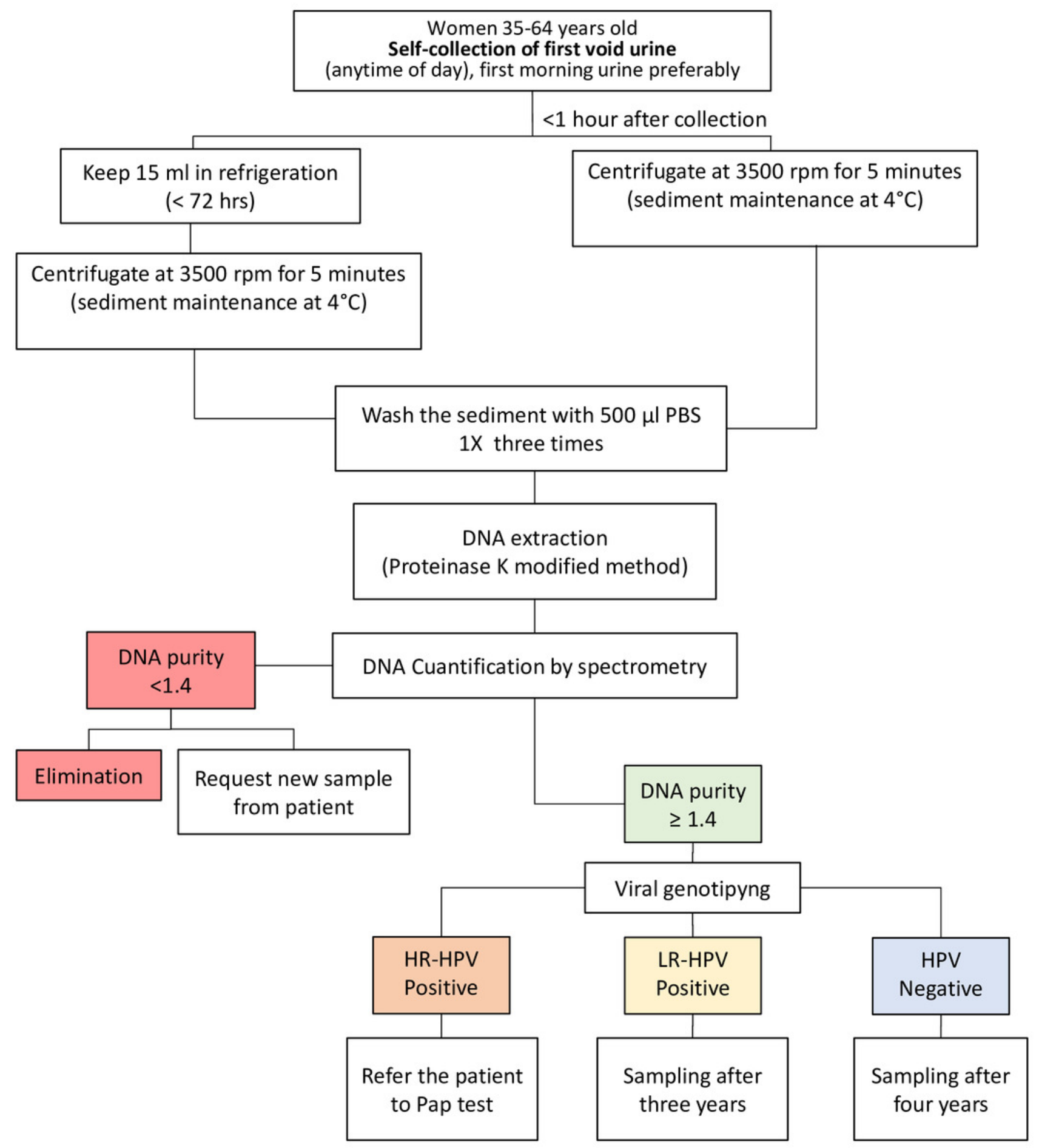

